\title{
A Fluorescent Probe for Investigating the Activation of Anticancer Platinum(IV) Prodrugs Based on the Cisplatin Scaffold**
}

\author{
Diego Montagner, Siew Qi Yap, and Wee Han Ang*
}

\author{
In memory of Elena Bertacco
}

Following the discovery of its potent antitumoral activity in 1965, the inorganic drug cisplatin has become one of the most important anticancer agents in clinical use. ${ }^{[1]}$ It exhibits exceptional activity against germ-cell testicular cancer, for which it is the first-line therapeutic option. ${ }^{[2]}$ Its success led to the development of second-generation drugs, namely carboplatin and oxaliplatin, both of which are also based on the cisdiam(m)ineplatinum(II) pharmacophore. Together, these FDA-approved $\mathrm{Pt}^{\mathrm{II}}$ drugs constitute some of the most widely used chemotherapeutic agents (Figure 1). ${ }^{[3]}$ Yet,

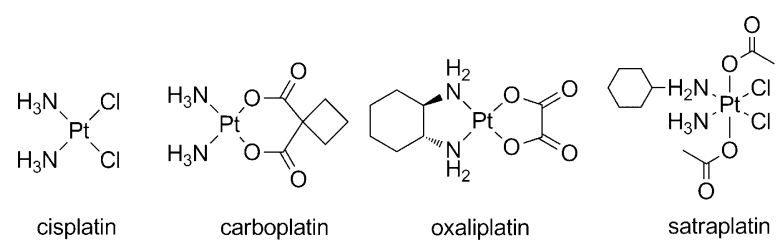

Figure 1. FDA-approved $\mathrm{Pt}^{\prime \prime}$ drugs and a $\mathrm{Pt}^{\mathrm{IV}}$ prodrug evaluated in clinical trials.

despite their clinical success, the use of $\mathrm{Pt}^{\mathrm{II}}$ drugs is limited by their high toxicity, severe side-effects, and incidences of drug resistance. ${ }^{[4]}$ To address some of these limitations, researchers have developed stable $\mathrm{Pt}^{\mathrm{IV}}$ carboxylate complexes as anticancer prodrugs that can be activated by intracellular reduction to release their latent cytotoxic activity. ${ }^{[5]}$ This versatile strategy has been used to develop $\mathrm{Pt}^{\mathrm{IV}}$ prodrug complexes with highly tuned properties, ${ }^{[6]}$ which are capable of targeting ${ }^{[7]}$ as well as delivering novel modes of action. ${ }^{[8]}$ The most prominent example is satraplatin, which is currently undergoing Phase III clinical trials against hormone-refractory prostate cancer (Figure 1). ${ }^{[9]}$ Although there is much interest in understanding and exploiting this prodrug strategy as a springboard towards the next generation of Pt drugs, tools capable of directly visualizing the uptake and

[*] Dr. D. Montagner, ${ }^{[+]}$S. Q. Yap, ${ }^{[+]}$Prof. Dr. W. H. Ang Department of Chemistry, National University of Singapore 3 Science Drive 3, Singapore (Singapore) E-mail: chmawh@nus.edu.sg

$\left[{ }^{+}\right]$These authors contributed equally to this work.

$[* *$ We acknowledge generous funding provided by A*STAR (TSRPiNPBi 1021520016), the National University of Singapore, and the Singapore Ministry of Education (R143-000-411-133 and R143-000 512-112) Supporting information for this article is available on the WWW under http://dx.doi.org/10.1002/anie.201305734. accumulation of these clinically important compounds are lacking. Herein, we describe a fluorescent probe that was custom-built for the detection of $\mathrm{Pt}^{\mathrm{II}}$ drugs such as cisplatin. Using confocal microscopy, we could determine the localization of the $\mathrm{Pt}^{\mathrm{IV}}$ prodrugs in cancer cells in vitro after cell entry and intracellular reduction.

Elucidating how $\mathrm{Pt}^{\mathrm{IV}}$ prodrugs are processed after cell entry would significantly improve our understanding of these compounds. Hambley et al. used elemental tomography to map the uptake of $\mathrm{Pt}^{\mathrm{IV}}$ prodrug complexes by tumor spheroids. Using X-ray near edge adsorption spectroscopy (XANES), they showed that cancer cells treated with $\mathrm{Pt}^{\mathrm{IV}}$ prodrugs contained both $\mathrm{Pt}^{\mathrm{IV}}$ and $\mathrm{Pt}^{\mathrm{II}}$ species. ${ }^{[10]}$ However, these techniques required synchrotron $\mathrm{X}$-ray radiation, and so cannot be applied to living cells. Elemental-analysis techniques, such as graphite-furnace atomic-absorption spectrometry (GF-AAS) and inductively coupled plasma mass spectrometry (ICP-MS), have also been used extensively to quantitate the $\mathrm{Pt}$ distribution in tissue or cellular compartments, but they cannot be applied in cellular imaging. ${ }^{[11]}$ More recently, NanoSIMS was used to map the accumulation of cisplatin and the multinuclear Pt drug candidate TriplatinNC in vitro, but it cannot distinguish between different $\mathrm{Pt}$ oxidation states $\quad($ NanoSIMS $=$ nanoscale secondary ion mass spectrometry). ${ }^{[12]}$

Fluorescence microscopy remains the most effective and accessible method for imaging at the cellular level. Using immunofluorescence, Lippard and co-workers demonstrated that, after administration, $\mathrm{Pt}^{\mathrm{IV}}$ prodrugs were capable of forming nuclear Pt-DNA adducts in vitro, which were their biological target. ${ }^{[13]}$ To visualize the reduction process, fluorophores have also been attached directly to the $\mathrm{Pt}^{\mathrm{IV}}$ scaffold, resulting in fluorescence quenching of its $\mathrm{Pt}^{\mathrm{II}}$ congener. ${ }^{[14]}$ Reduction was accompanied by a concomitant enhancement in fluorescence intensity, which, in principle, provides the most direct method for visualizing reduction. $\mathrm{Pt}$ complexes have also been labeled, either directly or through the use of post-labeling strategies, with fluorophores to study their intracellular distribution. ${ }^{[15]}$ However, modification of the $\mathrm{Pt}^{\mathrm{IV}}$ complexes with such bulky organic groups changes the pharmacophore and alters their uptake characteristics, thus rendering them different from cisplatin.

Therefore, an ideal imaging probe should be delinked from the Pt scaffold and yet be selective enough to distinguish between $\mathrm{Pt}^{\mathrm{IV}} / \mathrm{Pt}^{\mathrm{II}}$ within a complex cellular environment. Koide and Garner developed a fluorescein-based chemodosimeter that detects Pt through Tsuji-Trost allylic bond cleavage. ${ }^{[16]}$ The system required prior conversion of the $\mathrm{Pt}$ 
species into $\mathrm{Pt}^{0}$, but was capable of detecting cisplatin with high specificity in a range of buffer conditions. Using combinatorial library synthesis, Tae et al. also disclosed a rhodamine-triazole probe that is capable of detecting $\mathrm{Pt}^{\mathrm{II}}$ species such as cisplatin through the ring opening of its spirolactam motif. ${ }^{[17]}$

We reasoned that it would be possible to engineer a fluorescent probe specifically designed for the detection of $\mathrm{Pt}^{\mathrm{II}}$ drugs in a cellular environment by taking advantage of the difference in reactivity between the $\mathrm{Pt}^{\mathrm{IV}}$ prodrug and its $\mathrm{Pt}^{\mathrm{II}}$ congener. $\mathrm{As} \mathrm{Pt}^{\mathrm{IV}}$ prodrug complexes are kinetically inert because of their saturated coordination sphere and stable electronic configuration, we could design functional groups that would selectively interact with $\mathrm{Pt}^{\mathrm{II}}$ species. Examples of such functional groups include dithiocarbamates and dithiocarbamate esters. ${ }^{[18]}$ Indeed, in clinical trials, sodium diethyldithiocarbamate (NaDDTC) was found to sequester excess administered cisplatin, and to mitigate systemic toxicity induced by the therapy. ${ }^{[19]}$ Our strategy was to tether the non-fluorescent spirolactam form of rhodamine $\mathrm{B}$ (RhoB) to a recognition motif comprised of DDTC (Supporting Information, Scheme S1). The recognition motif would bind $\mathrm{Pt}^{\mathrm{II}}$ species through the dithiocarbonyl bond; thereby, the trans ligands are labilized for reactions with the spirolactam motif, and the fluorescence is selectively turned on. ${ }^{[20]}$

The target probe Rho-DDTC was prepared in three steps (Scheme S1). RhoB was treated sequentially with $\mathrm{POCl}_{3}$ and $\mathrm{NH}_{2} \mathrm{OH}$ to obtain hydroxamate derivative $\mathbf{1}$. Reaction with excess 1,2-dibromoethane in the presence of triethylamine as a base yielded $\mathbf{2}$, which was quantitatively converted into Rho-DDTC by a reaction with NaDDTC. The C2 spacer between the Rho and DDTC motifs was employed to facilitate positioning of bound $\mathrm{Pt}$ at the spirolactam upon DDTC-binding. Rho-DDTC was fully characterized by ${ }^{1} \mathrm{H}$ and ${ }^{13} \mathrm{C}$ NMR, ESI-MS, and single-crystal X-ray crystallographic analyses (see the Supporting Information). The spiro form was confirmed in solution by the presence of the ${ }^{13} \mathrm{C}$ resonance of the spiro $\mathrm{C}$ atom at ca. $65 \mathrm{ppm}\left(\mathrm{CDCl}_{3}\right.$ and $\left[\mathrm{D}_{6}\right] \mathrm{DMSO}$ ), as well as in the solid state (Figure 2, C8). The crystal structure shows that the thiocarbonyl group is oriented towards the spirolactam, presumably to minimize steric repulsion between the $\mathrm{NEt}_{2}$ substituent of the carbamate and the xanthine ring, thus affording a suitable binding configuration.

Detection of $\mathrm{Pt}^{2+}$ using Rho-DDTC was investigated in HEPES buffer (20 mu, pH 7.4, 30\% EtOH). The probe was stable over a large $\mathrm{pH}$ range (3.5-12) and hence compatible with physiological conditions (Figure $\mathrm{S} 4$ ). When $\mathrm{K}_{2} \mathrm{PtCl}_{4}$ was added as the $\mathrm{Pt}^{2+}$ source $(80 \mu \mathrm{M})$, a visible change from colorless to pink was observed after 5 min with a 60 -fold increase in absorbance at $\lambda_{\max }=565 \mathrm{~nm}$, as observed by UV/ Vis spectroscopy (Figure S5). A strong fluorescence turn-on response was also recorded at $\lambda_{\mathrm{em}}=584 \mathrm{~nm}\left(\lambda_{\mathrm{ex}}=490 \mathrm{~nm}\right)$ with a 65 -fold enhancement relative to the control. At $\mathrm{Pt}^{2+}$ concentrations between $10-80 \mu \mathrm{M}$, both absorbance and fluorescence increased linearly (Figure S6). Analysis of a Job's plot indicated maximum fluorescence intensity at a mole fraction of 0.5 , which suggests that Rho-DDTC interacted with $\mathrm{Pt}^{2+}$ in a 1:1 ratio (Figure S7). The selectivity

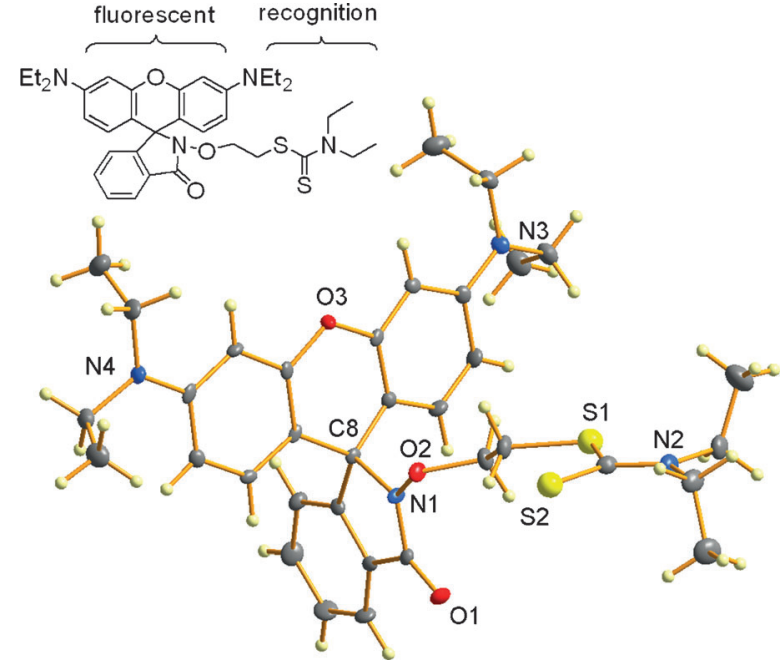

Figure 2. Molecular representation of Rho-DDTC; ellipsoids set at $50 \%$ probability.

of $\mathrm{Pt}^{2+}$ was high, as the use of other metal ions, such as $\mathrm{Na}^{+}$, $\mathrm{K}^{+}, \mathrm{Mg}^{2+}, \mathrm{Cu}^{2+}, \mathrm{Ni}^{2+}, \mathrm{Zn}^{2+}, \mathrm{Fe}^{2+}$, and $\mathrm{Fe}^{3+}$, which play important roles in biological systems, only led to baseline values in the emission and absorption spectra (Figure S8). Compared to $\mathrm{Pt}^{2+}$, the detection of cisplatin was slower under similar reaction conditions and required at least $60 \mathrm{~min}$ before a fluorescence signal could be measured. The selectivity for cisplatin compared to other metal ions remained high, even at elevated concentrations ( $\mathrm{Na}, \mathrm{K}$, and $\mathrm{Mg}$ at ca. $15 \mathrm{~mm}$ ), which is essential for its application as an intracellular probe (Figure S9).

To fully exploit Rho-DDTC as a probe for Pt drugs, we sought to understand its underlying mechanism of action. We postulated that aquation was essential for probe activation, because cisplatin readily undergoes aquation to form reactive aqua species. However, even after aquation was suppressed with $1 \mathrm{M} \mathrm{NaCl}$, the probe could still be activated, which thus suggests alternate pathways. Hence, we evaluated RhoDDTC against several cis- $\left[\mathrm{PtA}_{2} \mathrm{X}_{2}\right]$ scaffolds $\quad(\mathrm{A}=$ $\mathrm{am}(\mathrm{m})$ ine) to understand the role of the ligands in probe activation (Table S2). Intriguingly, when chelating A ligands were present, the $\mathrm{Pt}^{\mathrm{II}}$ complex could not activate the probe. To understand this observation, the reaction products of $\mathrm{K}_{2} \mathrm{PtCl}_{4}$, cisplatin, carboplatin, and JM118 with Rho-DDTC were analyzed by ESI-MS. The mass shifts indicated retention of an ammine and a cyclohexylamine ligand on the RhoDDTC/cisplatin and Rho-DDTC/JM118 adducts, respectively (Figure S10). JM118 exclusively formed adducts containing the cyclohexylamine ligand $(\mathrm{m} / \mathrm{z}$ 1057), whereas adducts with the alternate ammine ligand $(\mathrm{m} / \mathrm{z}$ 976) were absent. Furthermore, the same adducts were formed from cisplatin and carboplatin, which indicates that CBDCA was displaced.

Taken together, the data suggested that the displacement of an am(m)ine ligand is a critical step for Rho-DDTC activation. We reasoned that, in the absence of aquation, $\mathrm{Pt}^{\mathrm{II}}$ complexes first bind to a reactive DDTC motif with concomitant displacement of an ammine ligand (Scheme S2). 
The incident thiocarbonyl group labilizes $\mathrm{X}$ because of the trans effect; this induces nucleophilic attack on Pt by the spirolactam motif and activates the probe. As initial binding of JM118 would be affected by steric hindrance from cyclohexylamine, we expect the ammine ligand to be displaced. Furthermore, the chelating ethylenediamine (en) ligand confers kinetic stability to cis-[ $\left.\mathrm{Pt}(\mathrm{en}) \mathrm{Cl}_{2}\right]$, making displacement of the amine ligand unfavorable. Indeed, for oxaliplatin, probe activation was not observed, presumably because of its stable DACH chelate.

We therefore investigated the ability of Rho-DDTC to distinguish between $\mathrm{Pt}^{\mathrm{II}}$ drugs and their parental $\mathrm{Pt}^{\mathrm{IV}}$ complexes. In contrast to cisplatin, $\mathrm{Pt}^{\mathrm{IV}}$ complexes $3-\mathbf{6}$, which are based on the cisplatin template, did not trigger fluorescence turn-on (Figure 3 ). The reduction of $\mathrm{Pt}^{\mathrm{IV}}$ prodrug complexes

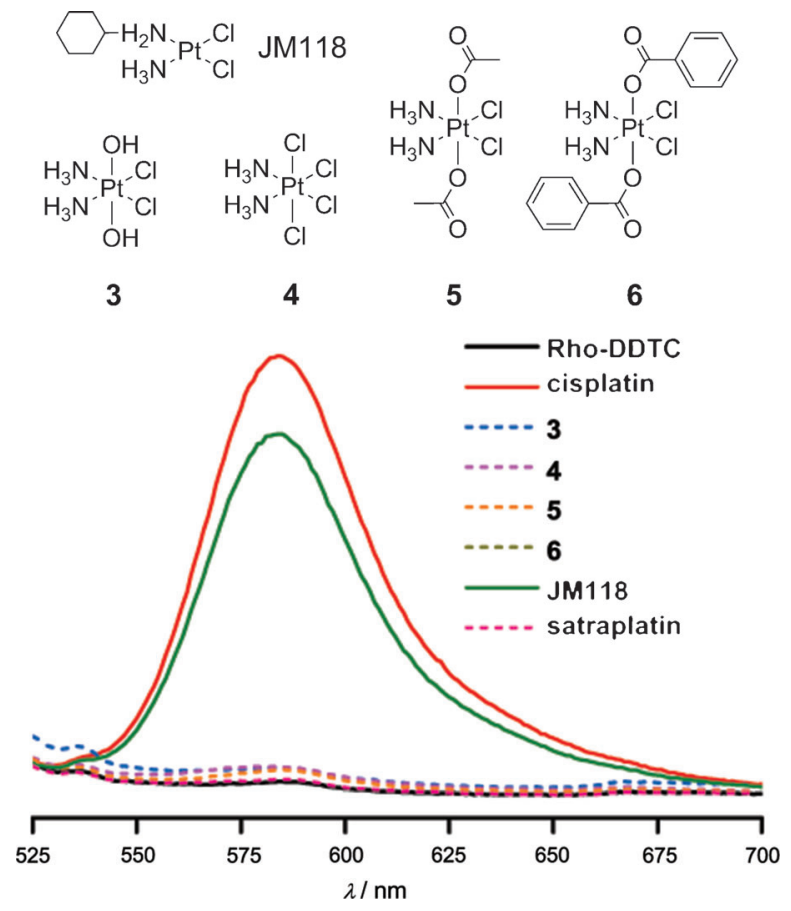

Figure 3. Fluorescence profile of Rho-DDTC $\left(\lambda_{\mathrm{ex}}=490 \mathrm{~nm}\right)$ after treatment with $\mathrm{Pt}^{\prime \prime}$ and $\mathrm{Pt}^{\mathrm{IV}}$ complexes in HEPES buffer.

is highly dependent on the nature of their axial ligands. Previous structure-activity relationship (SAR) studies have shown that complexes with axial chloride ligands are most readily reduced, followed by carboxylates, with hydroxo ligands being most resistant. ${ }^{[5 a, 21]}$ Rho-DDTC was robust enough to distinguish 4 from cisplatin. Similarly, Rho-DDTC could distinguish JM118 from satraplatin, both of which contain the asymmetric am(m)ine pharmacophore, thereby providing a direct way of investigating this clinically important drug candidate in biological systems.

We exposed HeLa cells to varying concentrations of cisplatin, from 0.5 to 10 times its $\mathrm{IC}_{50}$ value $(3 \mu \mathrm{M})$ for $3 \mathrm{~h}$ to establish the sensitivity of the probe. Treated live cells were incubated with Rho-DDTC, fixed with $4 \%$ paraformaldehyde, stained with Hoechst 33342 nuclear dye, and imaged under a confocal fluorescence microscope. Internalization of cisplatin was observed between two and ten times its $\mathrm{IC}_{50}$ value (Figure S11) and dispersed throughout the cytoplasm. We noted that the fluorescence did not co-localize with the nucleus stain because Rho-DDTC was unable to penetrate the nuclear compartment. We therefore applied our fluorescence detection system to image $\mathrm{Pt}^{\mathrm{II}}$ complexes $(30 \mu \mathrm{M})$ in HeLa cells to validate the observations. Intracellular fluorescence turn-on was achieved for cisplatin and JM118, which is consistent with the earlier selectivity tests (Figure 3; see also Figure S12). Oxaliplatin, which did not activate Rho-DDTC in buffer solution, was not observed in treated cells under these conditions (Figure S12). These tests demonstrated that the detection of $c i s-\left[\mathrm{PtA}_{2} \mathrm{X}_{2}\right]$ scaffolds by Rho-DDTC did not arise from non-specific interactions within the complex cellular environment.

The current understanding entails that anticancer $\mathrm{Pt}^{\mathrm{IV}}$ prodrugs are themselves inactive and require chemical reduction to cytotoxic $\mathrm{Pt}^{\mathrm{II}}$ species, although this has never been directly observed in live cells. ${ }^{[22]}$ This evidence was partially provided by a XANES study on frozen pellets of A2780 ovarian cancer cells that had been treated with $\mathrm{Pt}^{\mathrm{IV}}$ prodrug complexes at high concentrations $(200 \mu \mathrm{M})$, which quantitated a high proportion of $\mathrm{Pt}^{\mathrm{II}}$ species relative to $\mathrm{Pt}^{\mathrm{IV}}$ after $2 \mathrm{~h}$ of exposure. ${ }^{[10 \mathrm{~b}, 23]}$ We speculated that this rapid reduction occurs after cell entry within the cytoplasm. Complexes 3 and $\mathbf{6}$ were selected as representative $\mathrm{Pt}^{\mathrm{IV}}$ prodrug complexes at opposite ends of the activity spectrum. Complex 6 is hydrophobic $(\log P=1.01)$, whereas $\mathbf{3}$ is highly hydrophilic $(\log P=-2.81)$. Although both complexes are stable in culture media for $72 \mathrm{~h}, 3$ resisted reduction by virtue of its high reduction potential..$^{[6,23]}$

Cells treated with 3 and $\mathbf{6}(30 \mu \mathrm{M})$ exhibited fluorescence after $3 \mathrm{~h}$ of treatment, indicating fast conversion into $\mathrm{Pt}^{\mathrm{II}}$ species (Figure 4). Fluorescence in cells treated with $\mathbf{3}$ was

b)

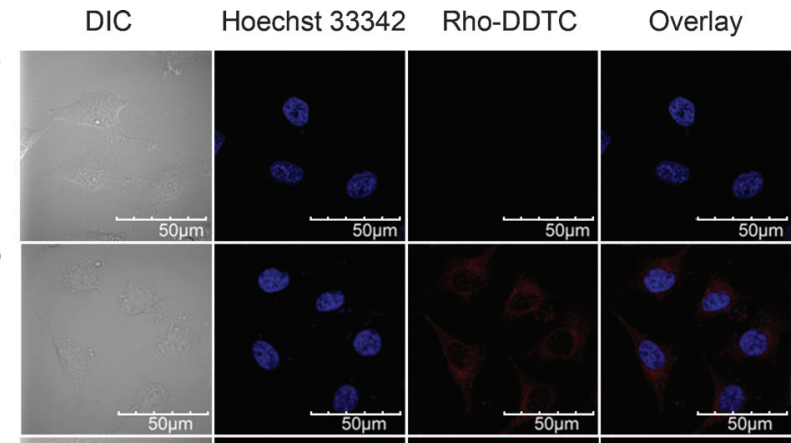

c)

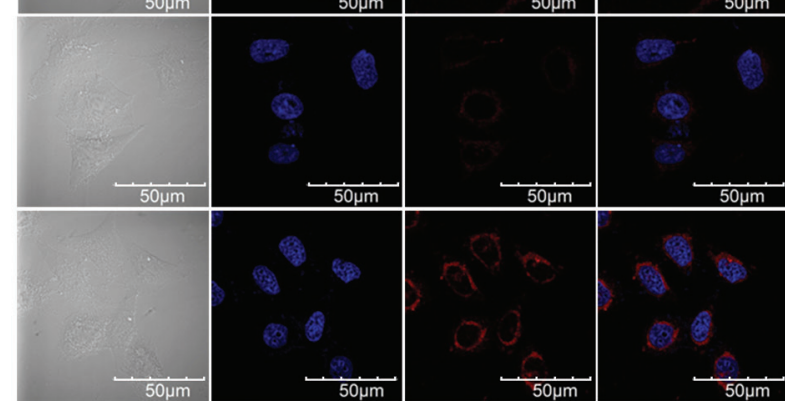

Figure 4. Merged fluorescence images of HeLa cells. a) Untreated (control), and exposed to b) cisplatin, c) 3, and d) $6(30 \mu \mathrm{M})$ for $3 \mathrm{~h}$ and further incubated with Rho-DDTC $(30 \mu \mathrm{m})$ for $1 \mathrm{~h}$ at $37^{\circ} \mathrm{C}$. 
well-dispersed within the cytoplasm, which is in line with the results obtained for cisplatin, but at lower levels. In contrast, the fluorescence profile observed for cells treated with $\mathbf{6}$ was more intense and concentrated around the outer nuclear envelope. This was presumably due to the highly hydrophobic nature of $\mathbf{6}$, which results in its accumulation at the nuclear lipid bilayer and is the subject of ongoing investigations. The strong fluorescence profile of cells treated with $\mathbf{6}$ instead of $\mathbf{3}$ indicated greater availability of the cytotoxic $\mathrm{Pt}^{\mathrm{II}}$ species in the intracellular region, and can account for the significant difference in cytotoxicity, with 6 more than 50 times more efficacious than 3. ${ }^{[6 \mathrm{~d}]}$ The probe was further validated against satraplatin and its $\mathrm{Pt}^{\mathrm{II}}$ metabolite, JM118. Satraplatin is more lipophilic than JM118 by virtue of two axial acetate ligands, which also improve its oral bioavailability. ${ }^{[24]}$ In line with the results obtained for other $\mathrm{Pt}^{\mathrm{IV}}$ carboxylates, cells treated with satraplatin exhibited a high intracellular fluorescence response, comparable to that obtained for JM118-treated cells (Figure S12). However, we noted that the orally administered satraplatin is only moderately stable in blood, and can be reduced to JM118 in vivo prior to cellular uptake. ${ }^{[25]}$ This probe could still be useful in addressing questions related to the circulation of satraplatin and its distribution to distal organ/tumor sites after oral administration.

In conclusion, we have developed a fluorescent turn-on probe rationally designed for the study of anticancer $\mathrm{Pt}$ complexes within live cells. The probe is compatible with biological conditions and designed to specifically target $\mathrm{Pt}^{\mathrm{II}}$ complexes containing the diam(m)ineplatinum(II) pharmacophore, including cisplatin. We found that the displacement of an amine ligand is a prerequisite for the activation of the fluorescence probe, and validated its selectivity between $\mathrm{Pt}^{\mathrm{II}}$ complexes with chelating and non-chelating amine ligands. The probe is also able to distinguish between $\mathrm{Pt}^{\mathrm{IV}}$ prodrug complexes and their $\mathrm{Pt}^{\mathrm{II}}$ products. For several $\mathrm{Pt}^{\mathrm{IV}}$ prodrugs, including satraplatin, we showed that reduction occurred after cell entry and that the $\mathrm{Pt}^{\mathrm{II}}$ products accumulated within the cytoplasm. In summary, Rho-DDTC is a versatile tool for the study of the localization of clinically important $\mathrm{Pt}^{\mathrm{II}}$ anticancer drugs and the activation of their $\mathrm{Pt}^{\mathrm{IV}}$ prodrug congeners within live cells.

Received: July 3, 2013

Published online: September 17, 2013

Keywords: cancer · confocal microscopy · fluorescence . platinum $\cdot$ prodrugs

[1] a) B. Rosenberg, L. Van Camp, T. Krigas, Nature 1965, 205, 698 699; b) B. Rosenberg, L. Van Camp, J. E. Trosko, V. H. Mansour, Nature 1969, 222, 385-386.

[2] A. Horwich, J. Shipley, R. Huddart, Lancet 2006, 367, 754-765.

[3] a) L. Kelland, Nat. Rev. Cancer 2007, 7, 573-584; b) D. Wang, S. J. Lippard, Nat. Rev. Drug Discovery 2005, 4, 307-320.

[4] M. A. Fuertes, C. Alonso, J. M. Perez, Chem. Rev. 2003, 103, $645-662$.

[5] a) M. D. Hall, H. R. Mellor, R. Callaghan, T. W. Hambley, $J$ Med. Chem. 2007, 50, 3403-3411; b) J. S. Butler, P. J. Sadler,
Curr. Opin. Chem. Biol. 2013, 17, 175-188; c) M. Galanski, M. A. Jakupec, B. K. Keppler, Curr. Med. Chem. 2005, 12, $2075-$ 2094.

[6] a) L. R. Kelland, B. A. Murrer, G. Abel, C. M. Giandomenico, P. Mistry, K. R. Harrap, Cancer Res. 1992, 52, 822-828; b) W. H. Ang, S. Pilet, R. Scopelliti, F. Bussy, L. Juillerat-Jeanneret, P. J. Dyson, J. Med. Chem. 2005, 48, 8060-8069; c) M. Reithofer, M. Galanski, A. Roller, B. K. Keppler, Eur. J. Inorg. Chem. 2006, 2612-2617; d) C. F. Chin, Q. Tian, M. I. Setyawati, W. Fang, E. S. Q. Tan, D. T. Leong, W. H. Ang, J. Med. Chem. 2012, 55, 7571-7582; e) J. Z. Zhang, P. Bonnitcha, E. Wexselblatt, A. V. Klein, Y. Najajreh, D. Gibson, T. W. Hambley, Chem. Eur. J. 2013, 19, 1672-1676.

[7] a) S. Abramkin, S. M. Valiahdi, M. A. Jakupec, M. Galanski, N. Metzler-Nolte, B. K. Keppler, Dalton Trans. 2012, 41, $3001-$ 3005; b) L. Gaviglio, A. Gross, N. Metzler-Nolte, M. Ravera, Metallomics 2012, 4, 260-266; c) D. Y. Q. Wong, J. Y. Lau, W. H. Ang, Dalton Trans. 2012, 41, 6104-6111; d) S. Mukhopadhyay, C. M. Barnes, A. Haskel, S. M. Short, K. R. Barnes, S. J. Lippard, Bioconjugate Chem. 2008, 19, 39-49.

[8] a) W. H. Ang, I. Khalaila, C. S. Allardyce, L. Juillerat-Jeanneret, P. J. Dyson, J. Am. Chem. Soc. 2005, 127, 1382-1383; b) K. R. Barnes, A. Kutikov, S. J. Lippard, Chem. Biol. 2004, 11, 557-564.

[9] H. Choy, Expert Rev. Anticancer Ther. 2006, 6, 973-982.

[10] a) R. A. Alderden, H. R. Mellor, S. Modok, M. D. Hall, S. R. Sutton, M. G. Newville, R. Callaghan, T. W. Hambley, J. Am. Chem. Soc. 2007, 129, 13400-13401; b) M. D. Hall, G. J. Foran, M. Zhang, P. J. Beale, T. W. Hambley, J. Am. Chem. Soc. 2003, $125,7524-7525$.

[11] a) A. R. Timerbaev, S. S. Aleksenko, K. Polec-Pawlak, R. Ruzik, O. Semenova, C. G. Hartinger, S. Oszwaldowski, M. Galanski, M. Jarosz, B. K. Keppler, Electrophoresis 2004, 25, 1988-1995; b) M. Groessl, O. Zava, P. J. Dyson, Metallomics 2011, 3, 591 599.

[12] L. E. Wedlock, M. R. Kilburn, R. Liu, J. A. Shaw, S. J. BernersPrice, N. P. Farrell, Chem. Commun. 2013, 49, 6944-6946.

[13] a) S. Dhar, F. X. Gu, R. Langer, O. C. Farokhzad, S. J. Lippard, Proc. Natl. Acad. Sci. USA 2008, 105, 17356-17361; b) S. Dhar, S. J. Lippard, Proc. Natl. Acad. Sci. USA 2009, 106, 2219922204.

[14] a) J. J. Wilson, S. J. Lippard, Inorg. Chim. Acta 2012, 389, 77-84; b) E. J. New, R. Duan, J. Z. Zhang, T. W. Hambley, Dalton Trans. 2009, 3092-3101.

[15] a) S. Ding, X. Qiao, J. Suryadi, G. S. Marrs, G. L. Kucera, U. Bierbach, Angew. Chem. 2013, 125, 3434-3438; Angew. Chem. Int. Ed. 2013, 52, 3350-3354; b) X. J. Liang, D. W. Shen, K. G. Chen, S. M. Wincovitch, S. H. Garfield, M. M. Gottesman, J. Cell. Physiol. 2005, 202, 635-641; c) C. Molenaar, J. M. Teuben, R. J. Heetebrij, H. J. Tanke, J. Reedijk, J. Biol. Inorg. Chem. 2000, $5,655-665$.

[16] A. L. Garner, K. Koide, Chem. Commun. 2009, 83-85.

[17] H. Kim, S. Lee, J. Lee, J. Tae, Org. Lett. 2010, 12, 5342-5345.

[18] a) L. Giovagnini, L. Ronconi, D. Aldinucci, D. Lorenzon, S. Sitran, D. Fregona, J. Med. Chem. 2005, 48, 1588-1595; b) D. Montagner, P. J. Sanz Miguel, Dalton Trans. 2011, 40, 1080910811.

[19] a) R. F. Borch, M. E. Pleasants, Proc. Natl. Acad. Sci. USA 1979, 76, 6611-6614; b) D. L. Bodenner, P. C. Dedon, P. C. Keng, J. C. Katz, R. F. Borch, Cancer Res. 1986, 46, 2751-2755; c) W. M. Awni, J. V. Hoff, B. E. Shapiro, C. E. Halstenson, J. Clin. Pharmacol. 1994, 34, 1183-1190.

[20] X. Chen, T. Pradhan, F. Wang, J. S. Kim, J. Yoon, Chem. Rev. 2012, 112, 1910-1956.

[21] M. D. Hall, S. Amjadi, M. Zhang, P. J. Beale, T. W. Hambley, J. Inorg. Biochem. 2004, 98, 1614-1624. 
[22] a) E. Wexselblatt, D. Gibson, J. Inorg. Biochem. 2012, 117, 220 229 ; b) A. Nemirovski, Y. Kasherman, Y. Tzaraf, D. Gibson, J. Med. Chem. 2007, 50, 5554-5556.

[23] M. D. Hall, H. L. Daly, J. Z. Zhang, M. Zhang, R. A. Alderden, D. Pursche, G. J. Foran, T. W. Hambley, Metallomics 2012, 4, $568-575$.
[24] a) S. Y. Sharp, P. M. Rogers, L. R. Kelland, Clin. Cancer Res. 1995, 1, 981 -989; b) H. Choy, C. Park, M. Yao, Clin. Cancer Res. 2008, 14, 1633-1638

[25] J. L. Carr, M. D. Tingle, M. J. McKeage, Cancer Chemother. Pharmacol. 2002, 50, 9-15. 